speaking background community groups have not been involved in these coordinated responses to domestic violence.This research established the need to work with specific cultural groups to address domestic violence. It successfully challenged the tolerance to domestic violence and showed that community involvement is crucial in designing culture-specific interventions. The study aimed to strengthen existing community capacity to address domestic violence within each community group by building on existing networks. The project was a balanced approach to providing communities with information and skills about how to respond to domestic violence and recognising and building on existing community strengths.

\section{REFERENCES}

1. Australian Bureau of Statistics (1996) Women's safety Australia (Cat. No. 4128.0). Canberra: Commonwealth of Australia, 1996.

2. Office of the Status of Women. Community attitudes to violence against women. Canberra: Department of the Prime Minister and Cabinet, 1995.

3. Strengthening attitudes opposing domestic violence in culturally diverse communities-Campaign report. 1998. Sydney: South Western and Central Sydney Area Health Services, 1998. ISBN 1875909 540. it?

\title{
SMOKING AND WOMEN
}

\section{Kate Purcell}

Principal Policy Officer

Public Health Legislation Project

NSW Department of Health

This article provides an overview of the effect of smoking on women and how health services can support women to quit.

For almost 60 years, until the recent restrictions on advertising, women have been exposed to images of smoking in a variety of media, including billboard advertisements, movies and women's magazines. Tobacco company documents confirm that the industry has spent large sums of money positioning smoking as a gateway to glamour, beauty, independence, a slim body, success and romance. In Australia, the industry aggressively marketed brands designed to appeal to teenage girls and young women.

In 1992, just over 5,000 Australian women died from tobacco-related illness (more than one woman every two hours), and lung cancer is second only to breast cancer as the most common cause of cancer deaths among women. Recent research indicates that women who smoke at the same level as men have a higher risk of developing lung cancer than men. ${ }^{1}$ Other research suggests that the younger people are when they take up smoking, the greater their chance of developing cancer later in life because early smoking appears to cause greater damage to DNA. ${ }^{2}$

Like men, women who smoke are likely to die of lung and other cancers, heart disease, stroke and respiratory diseases. In addition, women also experience genderspecific problems and additional health risks. These include:
- Menstrual problems and reduced fertility

Women who smoke more than 20 cigarettes a day are three times more likely than non-smokers to take more than a year to conceive and have a greater risk of ectopic pregnancy and miscarriage. ${ }^{3}$

- Increased risk of cancer of the cervix and vulva It has been estimated that 19 per cent of cervical cancer and 40 per cent of vulvar cancer is caused by smoking. ${ }^{4}$

- Increased risk of osteoporosis

For women who smoke 20 cigarettes a day through adulthood, bone density will have reduced by five to 10 per cent by the time they reach menopause. ${ }^{4}$

- Prenatal problems

Smoking women experience complications in pregnancy and labour, including a greater risk of miscarriage, premature labour and low-birth-weight babies. $^{4}$

\section{- Postnatal problems}

Children of smoking mothers are at increased risk of SIDS and childhood asthma. ${ }^{4}$

- Heart disease and stroke

Women who use oral contraceptives and who smoke have a tenfold increase in risk of heart disease and stroke compared to non-smokers. ${ }^{5}$

Health professionals have an important role in providing information and in encouraging and supporting women in their attempts to quit smoking. About 180,000 Australians quit smoking each year and, for most smokers, successful quitting usually takes a number of attempts.

After quitting, the body can rid itself of nicotine and carbon monoxide within a few hours and nicotine byproducts within a few days. Blood flow to the limbs improves within two months, and the lungs clean 
themselves within three months. ${ }^{6}$ If a woman gives up smoking by the 16th week of pregnancy, her risk of delivering a low-weight baby is similar to that of a nonsmoker. $^{7}$

The fear of gaining weight is often mentioned as an important issue for women smokers. In one survey, 25 per cent of women stated that a fear of gaining weight was a major factor discouraging them from quitting (twice the proportion of men). ${ }^{4}$ Weight gain may occur after quitting because of the absence of nicotine, which suppresses appetite and increases a person's metabolic rate. However, only 14 per cent of both male and female quitters report weight gain as a disadvantage once they have stopped smoking. ${ }^{4}$ Other research indicates that the average weight gain is about $2.3 \mathrm{~kg}^{7}$

Cessation advice for women should address their specific concerns. For some women, this may involve providing advice on making their home smoke-free and reducing exposure of children to passive smoking. For those who smoke 10 or more cigarettes a day, nicotine replacement therapy doubles a smoker's chance of a successful attempt to quit. Some women may seek advice and support during pregnancy, while many others, especially those concerned about gaining weight, could benefit from complementary advice about nutrition, exercise and stress management as part of a smoking cessation intervention.
Advice on quitting smoking is available from the Quitline on 131848 or the NSW Quit Campaign on 98180450.

\section{REFERENCES}

1. Harris RE, Zang EA, Anderson JI et al. Race and sex differences in lung cancer risk associated with cigarette smoking. Int J Epidemiol 1993; 22(4): 592-599.

2. NSW Cancer Council Web site: www.nswcc.org.au/pages/ tobacco/youth.htm.

3. Chollat-Traquet C. Women and tobacco. Geneva: World Health Organization, 1992.

4. Winstanley M, Woodward S, Walker N. Tobacco in Australia: Facts and Issues (second edition). Melbourne: Quit Victoria, 1995.

5. NSW Cancer Council Web site: ww.nswcc.org.au/pages/ tobacco/women.htm.

6. Commonwealth Department of Health, National Tobacco Campaign: 10 facts about smoking. www.quitnow.info.au/ fact.html.

7. Floyd RL, Rimer BK, Giovao GA, Mullen PD, Sullivan SE. A review of smoking and pregnancy: Effects on pregnancy outcomes and cessation efforts. Annu Rev Public Health 1993; 14: 379-411. W

\section{POSTNATAL DEPRESSION}

\section{Professor Philip Boyce}

Area Director of Mental Health

Wentworth Area Health Service

Up to 15 per cent of women suffer from an episode of depression in the first six months following childbirth. ${ }^{1}$ Postnatal depression is no different symptomatically from depression that arises at other times in the life cycle; its uniqueness and importance lies in its close association with childbirth and the predicability of it emerging after childbirth. $^{2}$

The causes of postnatal depression are predominantly psychosocial, with little evidence to support a hormonal cause. ${ }^{1}$ The physiological and emotional stresses associated with childbirth, and the role and identity changes a woman experiences along with the stress associated with caring for a new infant, act as the precipitant to depression among vulnerable individuals.
The key risk factors for women are: poor social support, particularly lack of emotional and, to a lesser extent, practical support from partners in caring for their babies; ${ }^{3}$ lack of other sources of practical support; having an anxious personality; and obstetric factors such as early discharge from hospital, ${ }^{4}$ a traumatic delivery or caesarean section. ${ }^{5}$

Recent research has found that postnatal depression has a profound impact on the healthy development of an infant. Infants of mothers suffering from postnatal depression may have impaired cognitive development and difficulty in forming attachments. The long-term sequelae of such developmental difficulties have not been researched; however, it is speculated that they contribute to the development of such common psychiatric disorders as depression, anxiety, and drug and alcohol problems. Postnatal depression may also be the first episode in a life-long pattern of recurrent depression for some women, and early intervention may prevent this from occurring. 